\title{
Leukocyte Antimicrobial Function in Patients with Leprosy
}

\author{
David J. Drutz, Martin J. Cline, and Louis Levy \\ From the Division of Infectious Diseases, San Francisco General Hospital, \\ San Francisco, California 94110; the Department of Medicine and the Cancer \\ Research Institute, School of Medicine, University of California, San Francisco, \\ California 94143; and the U. S. Public Health Service Hospital, \\ San Francisco, California 94118
}

\begin{abstract}
A в S TRACT Patients with lepromatous leprosy are unresponsive to lepromin skin-test material and possess defective lymphocyte function in vitro, including impaired mitogenesis in response to antigens of Mycobacterium leprae. It has been claimed that their macrophages cannot digest $M$. leprae in vitro; such a defect could explain both lepromin nonreactivity and impaired lymphocyte function on the basis of failure of the afferent limb of the immune response (i.e., defective macrophage "processing" of $M$. leprae).

The present studies indicate that macrophages from patients with lepromatous and tuberculoid leprosy and from normal donors do not differ in their ability to digest heat-killed $M$. leprae in vitro, or in their ability to sustain the viability of $M$. leprae in tissue culture; that monocytes, macrophages, and polymorphonuclear leukocytes of leprosy patients and controls possess equivalent microbicidal activity against Listeria monocytogenes, Escherichia coli, Proteus vulgaris, Staphylococcus aureus, and Candida albicans; and that polymorphonuclear leukocytes from patients with lepromatous leprosy iodinate ingested bacteria normally. Whether the basic immune defect leading to the development of lepromatous leprosy resides in the lymphocyte or in the macrophage remains to be determined. However, the present study shows that phagocytic cells from patients with either principal form of leprosy function normally in a variety of sophisticated tests of antimicrobial function.
\end{abstract}

\section{INTRODUCTION}

According to current concepts, resistance to intracellular pathogens is dependent upon interactions between lym-

Dr. Cline's present address is the Division of Hematology-Oncology, Department of Medicine, School of Medicine, University of California, Los Angeles, California 90024.

Reccized for publication 26 July 1973 and in revised form 1 October 1973. phocytes and macrophages (1). Lymphocytes sensitized to antigens of invading microorganisms provide the stimulation necessary to activate macrophages, which are nonspecific effector cells for microbial ingestion and destruction $(2,3)$. Conversely, localization of microbial antigen within or on macrophages may be necessary to augment the initial lymphocyte response $(4,5)$. In theory, a defect in either cell population could result in enhanced susceptibility to infection with intracellular pathogens.

In patients with lepromatous leprosy, function of lymphocytes is abnormal in that there is impaired response to skin-test antigens, prolonged survival of skin homografts, and reduced lymphocyte reactivity to mitogenic agents $(6,7)$. These defects are superficially similar to those found in patients with sarcoidosis (8) and Hodgkin's disease (9). However, many of these abnormalities are reversible with successful treatment of the infection, and may represent superimposed qualitative and quantitative abnormalities of the thymus-derived-lymphocyte population (10). Unresponsiveness to the antigens of Mycobacterium leprae appears to be the only immunologic abnormality entirely specific for patients who develop disseminated leprosy (11).

In 1967 Barbieri and Correa reported that macrophages from patients with lepromatous leprosy were incapable of digesting heat-killed $M$. leprae, whereas cells from patients with tuberculoid leprosy digested the microorganisms completely (12). At the same time Beiguelman (13) suggested that an inherited digestive defect of macrophages specific for $M$. leprae might explain the occurrence in certain persons of the disseminated (lepromatous) form of leprosy. Nonreactivity to lepromin might then be explained on the basis of defective macrophage "processing" of $M$. leprae, that is, on failure of the afferent limb of the immune response.

In the present study, we examined monocytes and macrophages of patients with leprosy for three aspects of 
functional activity (general bactericidal activity, ability to digest heat-killed $M$. leprae, and ability to sustain the viability of $M$. leprae in tissue culture) in order to ascertain whether a primary defect of mononuclear phagocytes exists in patients with lepromatous leprosy. We also examined the ability of polymorphonuclear leukocytes from these patients to kill bacteria and fungi.

\section{METHODS}

\section{Patients}

Blood was obtained from patients hospitalized on the Leprosy Service, U. S. Public Health Service Hospital, San Francisco. Patients were classified as having lepromatous, borderline, or tuberculoid leprosy. ${ }^{1}$ All patients were fully informed of the nature of the study to be undertaken. For control studies, blood was obtained from paid volunteers.

\section{Preparation of leukocytes}

Monocytes and macrophages. Heparinized (Lipo-Hepin, Riker Laboratories, Inc., Northridge, Calif.; phenol-free) peripheral blood specimens were sedimented with $3 \%$ dextran (mol wt 100,000-200,000; Nutritional Biochemicals Corporation, Cleveland, Ohio). The washed, leukocyte-rich supernate was suspended in $20 \%$ fetal calf serum (FCS $)^{2}$ in McCoy's medium (Grand Island Biological Co., Oakland, Calif.) to a concentration of $2-5 \times 10^{8}$ monocytes $/ \mathrm{ml}$. A series of Leighton tubes containing removable cover slips was inoculated with $1-\mathrm{ml}$ samples of the cell suspension. $3 \mathrm{~h}$ later the medium was changed to McCoy's medium containing $30 \%$ human $\mathrm{AB}$ serum (ABM) without antibiotics. Bactericidal capabilities of monocytes and polymorphonuclear leukocytes (PMN) were measured at this time by a tritiated thymidine $\left(\left[{ }^{3} \mathrm{H}\right] \mathrm{T}\right)$ assay that allows evaluation of individual cell types in mixed leukocyte populations (15).

Macrophages were obtained by allowing monolayers to develop for an additional $3-10$ days at $37^{\circ} \mathrm{C}$ with or without penicillin G, $50 \mu \mathrm{g} / \mathrm{ml}$. Lymphocytes do not stick to glass, and granulocytes generally die and leave the cover slip within 2-3 days; thus, a nearly pure monolayer of mononuclear phagocytes remains after 3 days. On the day of the experiment, monolayers were washed six times in warm Hanks' balanced salt solution (HBSS), fresh ABM without antibiotics was added, and cells were allowed to equilibrate at $37^{\circ} \mathrm{C}$ for $2 \mathrm{~h}$ before use in the ${ }^{22} \mathrm{P}$ microbicidal assay (16). Macrophages grown in the presence of penicillin were washed twice: once the day before and once the day of the experiment.

$P M N$. When PMN were required for fungicidal studies, the leukocyte-rich supernate from dextran-sedimented

\footnotetext{
${ }^{1}$ Lepromatous patients included those with lepromatous and borderline lepromatous leprosy by the Ridley-Jopling classification (14). Tuberculoid patients included those with borderline tuberculoid and tuberculoid leprosy. Patients with borderline leprosy were those classified as borderline-borderline by the Ridley-Jopling method.

'Abbreviations used in this paper: ABM, McCoy's medium containing $30 \%$ human $\mathrm{AB}$ serum; CFU, colonyforming unit; ENL, erythema nodosum leprosum; FCS, fetal calf serum; HBSS, Hanks' balanced salt solution; PMN, polymorphonuclear leukocytes; $\mathrm{T}$, thymidine.
}

blood was centrifuged at $150 \mathrm{~g}$ for $10 \mathrm{~min}$ and washed twice with HBSS containing $10 \% \mathrm{FCS}$ and $5 \mathrm{U}$ of heparin $/ \mathrm{ml}$. Leukocyte and absolute PMN concentrations were determined by hemocytometer count. Just before addition to the assay, the leukocytes were centrifuged at $150 \mathrm{~g}$ for $8 \mathrm{~min}$ and suspended in HBSS at a concentration of $10^{7} \mathrm{PMN} /$ $\mathrm{ml}$.

\section{Tests of leukocyte function}

$\left.{ }^{3} H\right] T$ bactericidal assay (PMN and monocyte studies). This technique is based upon the principle that bacteria that are viable and engaged in synthetizing DNA will incorporate $\left[{ }^{3} \mathrm{H}\right] \mathrm{T}$, even if they are situated within cells $(15,17)$. Log phase strains of Listeria monocytogenes, strain UCLM-1 (16), and Staphylococcus aureus, strain 502A, and clinical isolates of Escherichia coli and Proteus vulgaris were inoculated $\left(3-5 \times 10^{7}\right.$ bacteria/ml) into Leighton tubes containing mixed leukocytes. After a $30-\mathrm{min}$ period for phagocytosis, monolayers were washed to remove extracellular bacilli, and fresh ABM containing $\left[{ }^{8} \mathrm{H}\right] \mathrm{T}$ (sp act $2 \mathrm{Ci} / \mathrm{mmol}$; New England Nuclear, Boston, Mass.) was added. 30 min later the monolayer was washed thoroughly with HBSS containing cold T, fixed in methanol, dried overnight, dipped in NTB-2 autoradiography emulsion (Eastman Kodak Co., Rochester, N. Y.), exposed at $4^{\circ} \mathrm{C}$ for 4-7 days, developed in Kodak D19, and stained with Giemsa. Control tubes containing microorganisms and $\mathrm{ABM}$ without leukocytes were pulsed with $\left[{ }^{3} \mathrm{H}\right] \mathrm{T}$ in similar fashion and harvested by centrifugation with washing. Slides were examined by light microscopy. Viable replicating microorganisms had an overlying silver grain, while nonreplicating bacteria had no associated label. The percentage of microorganisms "killed" by phagocytes in this assay was calculated on the basis of the proportions of intracellular microorganisms and control microorganisms labeled with $\left[{ }^{3} \mathrm{H}\right] \mathrm{T}(15)$.

"P bactericidal assay (macrophage studies). This technique has been described in detail (16). ${ }^{32} \mathrm{P}$-labeled $L$. monocytogenes were added to monolayers of human macrophages 3-10 days old, in concentrations of $2-5 \times 10^{7}$ bacteria $/ \mathrm{ml}$ (estimated ratio of bacteria to cells, 10:1). After a 90 -min period for phagocytosis (the lag phase of Listeria in $\mathrm{ABM}$ is at least $120 \mathrm{~min}$ ), the cells were washed free of extracellular bacilli and disrupted by ultrasound. The sonically treated suspensions were diluted in ZoBell's solution and the proportion of surviving bacteria was determined by triplicate cultures on pour plates of trypticase agar. 1-ml samples of the sonically treated material were also taken for liquid scintillation counting in order to calculate the number of cell-associated radioactive bacteria originally present. A standard curve was developed to determine the number of colony-forming units (CFU) equivalent to a given amount of radioactivity. The percentage of cell-associated Listeria killed was determined by the calculation: \% Listeria killed $=[C F U$ (cell-associated) - CFU (observed) ] $\times 100 / \mathrm{CFU}$ (cell-associated).

Candida dye-exclusion assay (PMN studies). Candidacidal activity of PMN was measured by a previously described technique that evaluates viability of Candida albicans as a function of their ability to exclude methylene blue dye (18). Equal volumes $(0.25 \mathrm{ml})$ of human AB serum, suspended leukocytes, yeast-phase C. albicans, strain 820 (18), $10^{7} / \mathrm{ml}$, and HBSS were added to sterile plastic tubes $(12 \times 75 \mathrm{~mm})$ in duplicate experiments and rotated at $37^{\circ} \mathrm{C}(30 \mathrm{rpm})$ for $60 \mathrm{~min}$. Ingestion was complete at 15 min. At $60 \mathrm{~min}$, leukocytes were lysed by the addition of 


\section{NO ANTIBIOTIC PENICILLIN-EXPOSED}

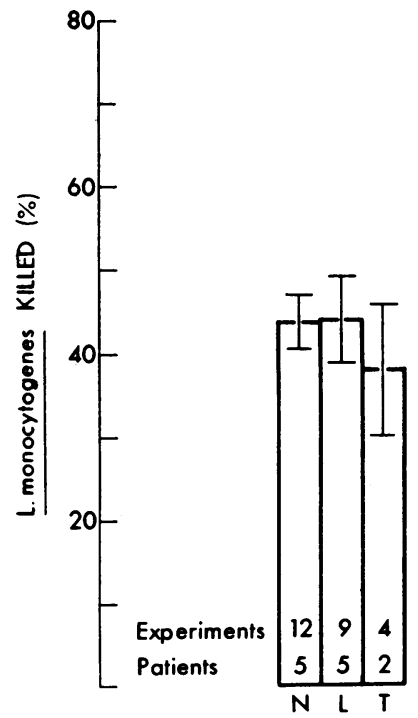

FIGURE 1 Bactericidal capability of macrophages from normal subjects (N) and patients with lepromatous (L) and tuberculoid (T) leprosy. Macrophages were grown either in the absence of an antibiotic (left) or in the presence of penicillin $\mathrm{G}, 50 \mu \mathrm{g} / \mathrm{ml}$ (right). Penicillin-containing medium was replaced with fresh antibiotic-free ABM $24 \mathrm{~h}$ and $2 \mathrm{~h}$ before use of the cells in an experiment. Experiments were performed using ${ }^{32} \mathrm{P}$-labeled $L$. monocytogenes. Results are expressed as mean $\pm \mathrm{SEM}$.

Penicillin-exposed macrophages from donors with lepromatous leprosy were significantly more bactericidal than penicillin-exposed cells from normal donors $(P<0.001$, Student's $t$ test). There were no other significant differences among groups.

$0.25 \mathrm{ml}$ of $2.5 \%$ sodium deoxycholate ( $\mathrm{pH} 8.7$ ). Methylene blue, $0.01 \%$ in distilled water, was then added to achieve a final volume of $4-5 \mathrm{ml}$, fungi were sedimented at $1,100 \mathrm{~g}$ for $15 \mathrm{~min}$, and the proportion of stained Candida in the resuspended button was compared with that in control tubes without leukocytes.

Standard microbicidal assay. With mixed leukocytes suspended in $\mathrm{ABM}$, standard microbicidal assays were performed by the method of Hirsch and Strauss (19) with $S$. aureus 502A and a ratio of bacteria to PMN of $2: 1$.

Microbial iodination. The ability of PMN and monocytes to iodinate intracellular bacteria was examined by the radioautographic method of Klebanoff and White (20) with $L$. monocytogenes, $S$. aureus 502A, E. coli, and $P$. vulgaris at a ratio of bacteria to cells of $3: 1$ or $5: 1$.

Digestion of heat-killed M. leprae. Monolayers of macrophages, 6-7 days old, were inoculated with $1.0-3.6 \times 10^{8}$ washed, heat-killed $M$. leprae (21) in $30 \%$ ABM containing $50 \mu \mathrm{g} / \mathrm{ml}$ of penicillin $\mathrm{G}$ together with either streptomycin $(50 \mu \mathrm{g} / \mathrm{ml})$ or nystatin $(50 \mathrm{U} / \mathrm{ml})$. The approximate ratio of bacteria to macrophages was $1: 1$. After incubation for $4 \mathrm{~h}$ at $37^{\circ} \mathrm{C}$ to allow phagocytosis, fresh $\mathrm{ABM}$ containing antibiotics but no bacteria was substituted and cells were incubated for 2 wk in the same medium. Cover slips were removed at intervals, fixed in $10 \%$ methanol, and stained by the Ziehl-Neelson technique.
Preliminary experiments with $M$. leprae in ABM without macrophages revealed no changes in morphologic appearance of bacteria during a 2-wk period. Mycobacteria were evaluated by the methods developed by Chang and Andersen for $M$. lepraemurium: Bacteria were categorized according to nine morphologic patterns ranging from "solid" through various stages of irregular staining (22). All slides were examined at a magnification of $1,600 \times$ with Köhler illumination. At least 200 bacteria were counted on each slide.

Maintenance of viability of $\mathrm{M}$. leprae in tissue cuiture. 1 -wk-old monolayers of macrophages were inoculated with $1.0-3.6 \times 10^{8}$ viable $M$. leprae (21) in $30 \%$ ABM containing $50 \mu \mathrm{g}$ of penicillin $\mathrm{G}$ and $50 \mathrm{U}$ of nystatin/ml. Control tubes without macrophages received identical inocula. After undisturbed incubation at $37^{\circ} \mathrm{C}$ for $3-15$ days, culture medium was removed, monolayers were lysed with cold, sterile, distilled water, and the lysate was recombined with the original tissue culture medium from each tube so that no leprosy bacilli were lost. The right hind footpads of $\mathrm{BALB} / \mathrm{c}$ mice were inoculated with $5 \times 10^{3}$ of the recovered $M$. leprae by methods that have been described (21). 20 mice were inoculated with leprosy bacilli from each Leighton tube. Methods for evaluating footpad multiplication of $M$. leprae have been described (21).

\section{RESULTS}

Bactericidal activity of macrophages. There were no differences among macrophages from normal individuals and patients with tuberculoid or lepromatous leprosy in their ability to kill $L$. monocytogenes when the cells had been grown in the absence of penicillin G (Fig. 1). However, when cells had been grown in penicillin-containing medium, those from patients with lepromatous

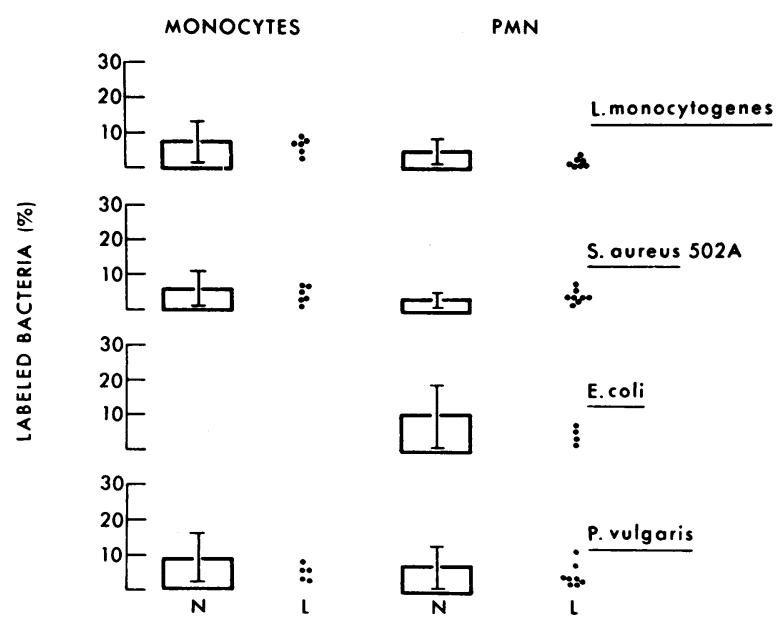

FIGURE 2 Bacterial inhibitory capability of monocytes (left) and PMN (right) from normal donors (N) and patients with lepromatous leprosy (L) against four microorganisms. The proportion of bacteria labeled $\left(\left[{ }^{3} \mathrm{H}\right] \mathrm{T}\right.$ assay) by normal cells (11-15 experiments from as many donors) is expressed as mean $\pm 2 \mathrm{SD}$. Dots are results of bacterial inhibitory tests of cells from individual patients with lepromatous leprosy. The mean of triplicate tests is shown for each patient. 
leprosy had significantly greater listericidal activity ( $P<0.001$ by Student's $t$ test $)$ than those from normal donors.

Bacterial inhibitory and candidacidal activity of monocytes and PMN. As measured by suppression of incorporation of $\left[{ }^{8} \mathrm{H}\right] \mathrm{T}$ into DNA, monocytes and PMN from lepromatous patients possessed normal inhibitory. activity against all bacterial strains tested (Fig. 2).

Leukocytes (primarily PMN) from three lepromatous patients were tested for their ability to kill $S$. aureus $502 \mathrm{~A}$ by standard colony-count assays (19). Within 60 $\min , 91,96$, and $98 \%$ of the ingested organisms were nonviable. All these values were within the normal range. Iodination of ingested bacteria by the phagocytic leukocytes from these patients was qualitatively normal (20).

There were no significant differences in the candidacidal activity of PMN from normal donors and patients with various forms of leprosy (Fig. 3). However, cells from patients with lepromatous leprosy complicated by erythema nodosum leprosum (ENL) killed Candida less well than those from patients with other forms of leprosy.

M. leprae-digestive capability of macrophages. The morphologic effects of intracellular residence of heatkilled $M$. leprae were examined as a function of the type of leprosy of the macrophage donor (Fig. 4). At $6 \mathrm{~h}$, morphologic appearance of the bacteria was nearly identical in cells of the normal subject and the three patients studied; $13 \%$ of mycobacteria were solid, as defined by full, smooth staining in length, width, and depth. After 12 days of incubation, macrophages in all tubes appeared equivalent in terms of density, morphologic appearance, and content of $M$. leprae (1-3/macrophage). There were discernible alterations in morphologic appearance of bac-

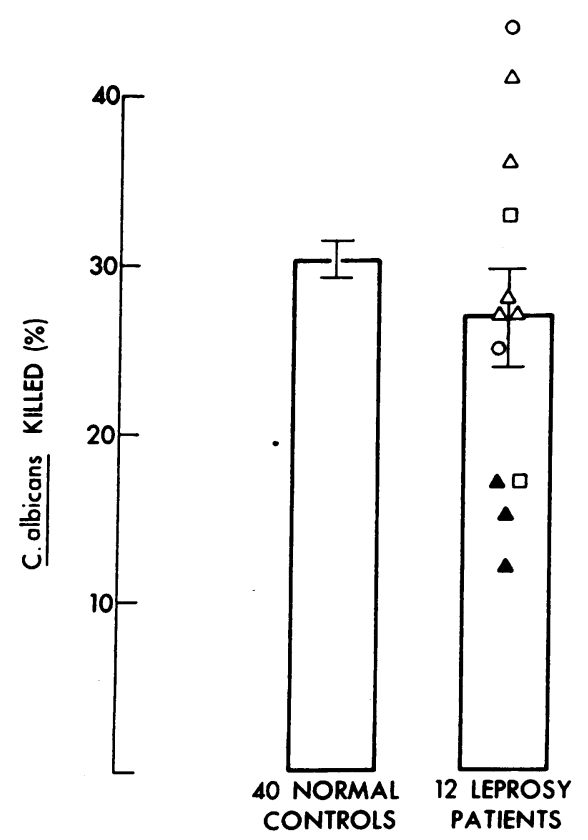

FIGURE 3 Candidacidal capability of polymorphonuclear leukocytes from normal subjects (left) and patients with various forms of leprosy (right) ; $O$, tuberculoid; $\square$, borderline; $\Delta$, lepromatous; $\Delta$, lepromatous with ENL. Results are expressed as mean $\pm S E M$, and individual values are also shown for cells of leprosy patients. There was no statistical difference between normal controls and patients $(0.1<P<0.2$; Student's $t$ test $)$.

teria, but such differences among the macrophages from different donors were slight. There were fewer solid microorganisms than were present originally, and there was an increase in the proportion of bacteria appearing segmented and as chains of two dots. The morphologic appearance of bacteria that had been released into the

\begin{tabular}{|c|c|c|c|c|c|c|c|c|c|c|c|}
\hline \multirow[b]{2}{*}{ PATIENT } & \multirow[b]{2}{*}{$\begin{array}{l}\text { TIME SLIDES } \\
\text { EXAMINED }\end{array}$} & \multirow[b]{2}{*}{$\begin{array}{l}\text { NO. SLIDES } \\
\text { EXAMINED }\end{array}$} & \multirow[b]{2}{*}{ Solid } & \multicolumn{7}{|c|}{ M.leproe OF EACH MORPHOLOGIC TYPE (\%) } & \multirow[b]{2}{*}{ Curved } \\
\hline & & & & 1 dot & 2 dots & $\begin{array}{c}\text { Pointed } \\
\text { ends }\end{array}$ & $\begin{array}{l}\text { Chain } \\
2 \text { dots }\end{array}$ & $\begin{array}{c}\text { Chain } \\
>2 \text { dots } \\
\end{array}$ & Segm. & $\begin{array}{l}\text { Irreg. } \\
\text { stoin }\end{array}$ & \\
\hline $\mathbf{N}$ & 6h & 1 & $\dddot{~}$ & $\bar{z}_{i}$ & $=$ & 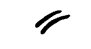 & $\because$ & 3 & - ii & זִים & $F$ \\
\hline $\mathbf{l}$ & $6 \mathrm{~h}$ & 1 & & & & & & & & & \\
\hline l & $6 h$ & 1 & 13 & 14 & 1.5 & 3.5 & 16 & 18.5 & 4 & 19.5 & 10 \\
\hline$T$ & $6 \mathrm{~h}$ & 1 & & & & & & & & & \\
\hline$N$ & 12 days & 5 & 8 & 14 & 5 & 3 & 22 & 19 & 11 & 12.5 & 5.5 \\
\hline$\iota$ & 12 days & 4 & 9 & 15.5 & 4.5 & 3.5 & 24.5 & 17 & 8 & 12 & 6 \\
\hline$t$ & 12 days & 4. & 5 & 13 & 5 & 3 & 25 & 16.5 & 11.5 & 14 & 7 \\
\hline$T$ & 12 days & 3 & 4 & 14 & 2 & 2 & 31 & 14 & 8 & 18 & 7 \\
\hline
\end{tabular}

Figure 4 Digestive ability of monolayers of macrophages from four subjects, one control $(N)$, two patients with lepromatous (L), and one with tuberculoid (T) leprosy. Cells were inoculated with heat-killed $M$. leprae after incubation for 7 days. Cells and bacteria were incubated at $37^{\circ} \mathrm{C}$ for $6 \mathrm{~h}$ or 12 days without an intervening change of medium. 
TABLE I

Days to Plateau Phase* of M. leprae in Footpad of Mouse as a Function of Duration of Previous Incubation in Cultured Macrophages

\begin{tabular}{lcccc}
\hline & \multicolumn{4}{c}{ Duration of incubation } \\
\cline { 2 - 5 } \multicolumn{1}{c}{ Source of macrophages } & 0 days & 3 days & 10 days & 15 days \\
\hline None (ABM only) & $118-125$ & 122 & days & 196 \\
Normal donors (2) & & 159,166 & 200 & 232 \\
Lepromatous leprosy (4) & & 164,176 & 190,222 & $191,191,195$, \\
Tuberculoid leprosy (2) & & & $199,242,256$ \\
& & & & 212,227 \\
\hline
\end{tabular}

* Time to plateau phase (time required for $M$. leprae to reach a plateau phase of multiplication in the mouse footpad) is expressed as a function of duration of residence in macrophages in vitro before inoculation into the footpad. Multiplication of $M$. leprae in the footpad follows a typical pattern. After inoculation of $5 \times 10^{3}$ bacilli, there is a "lag phase" of ap-. proximately 60 days. Subsequently, there is a period of logarithmic multiplication (generation time, 12 to 13 days) until a plateau, somewhat greater than $10^{6}$ bacilli per footpad, is reached. Under the conditions of this experiment, time to plateau is proportional to the number of viable microorganisms in each inoculum $(23,24)$. Results are those of individual experiments.

supernate from dead macrophages was not examined. In no case was there disappearance of mycobacteria from a macrophage monolayer.

The results of a second experiment using slightly different criteria for fragmentation gave nearly identical results. Here, the proportion of grossly fragmented bacteria rose from $10 \%$ to $23 \%$ in lepromatous macrophages, and from $9 \%$ to $17 \%$ in tuberculoid macrophages after 10 days of incubation. Normal donor macrophages survived in tissue culture only 6 days in this experiment.

Intracellular survival of viable $\mathrm{M}$. leprae. Leprosy bacilli survived for periods of up to 15 days within macrophage cultures from normal controls and patients with tuberculoid and lepromatous leprosy as evidenced by their ability to multiply subsequently in mouse footpads (Table I). However, intracellular residence appeared detrimental to bacterial survival because $M$. leprae maintained in ABM without cells usually grew better in the mouse footpad (i.e., required less time to reach plateau phase) than those that had been macrophage-passaged. There were no important differences among the three cell sources in terms of their ability to sustain viability of $M$. leprae.

\section{DISCUSSION}

Our results show no important differences between patients with tuberculoid and lepromatous leprosy and normal control subjects in the bactericidal and fungicidal functions of their phagocytic cells. The presence, in cells from patients with leprosy, of normal microbicidal function against microorganisms other than $M$. leprae is not surprising. Although patients with advanced lepromatous leprosy possess defects in cell-mediated immunity that resemble those found in Hodgkin's disease and sarcoidosis, they do not appear to share the propensity to opportunistic infection found in the other two diseases (25-27). Tuberculosis and hepatitis-associated antigen (Australia antigen) occur with increased frequency in patients with leprosy $(28-31)$, but this may reflect environmental factors related to institutionalization rather than an immunologic predisposition to infection.

The only difference encountered between lepromatous and other macrophages in bactericidal activity was the apparently paradoxical observation that macrophages from patients with lepromatous leprosy, when grown in penicillin-containing medium, possessed enhanced listericidal activity as compared with normal control macrophages that had been similarly cultivated. The strain of $L$. monocytogenes used in these studies was quite penicillin-sensitive (minimal inhibitory concentration, $0.2 \mu \mathrm{g} /$ $\mathrm{ml}$; minimal bactericidal concentration, $0.8 \mu \mathrm{g} / \mathrm{ml}$ ), and it is possible, but unlikely, that small amounts of penicillin were carried over with the cells, despite two replacements with antibiotic-free medium before their use in an experiment. The superior Listeria-killing activity of lepromatọus cells, among all those which had been grown in the presence of penicillin, suggests that lepromatous macrophages were more efficient accumulators of penicillin. In animal experiments, "immune" peritoneal macrophages have shown superior mycobactericidal capacity by virtue of their ability to concentrate streptomycin in vitro (32). It is possible that lepromatous macrophages are also "activated" by constant exposure to leprosy bacilli, which they cannot eradicate, and 
that this activation is reflected by their enhanced accumulation of penicillin in vitro.

Barbieri and Correa reported the presence of a highly specific macrophage digestive defect in patients with lepromatous leprosy (12). Tuberculoid macrophages were said to lyse and digest $M$. leprae within 10-16 days of their introduction into macrophage cultures, but lepromatous macrophages could not efficiently digest the microorganisms during this time. These observations suggested that an intrinsic defect of macrophages may predispose to the dissemination of leprosy. Our studies, and those recently reported by Godal and Rees (33), do not substantiate the presence of such a defect in lepromatous cells. The reported differences in the digestive capacity of tuberculoid and lepromatous macrophages may result from contamination of macrophage cultures by lymphocytes. Lymphocytes from tuberculoid, but not lepromatous, patients might respond to the presence of $M$. leprae by producing lymphokines, one function of which might be to enhance digestive capabilities of macrophages. (Our cultures contained few, if any, lymphocytes.) Godal, Rees, and Lamvik (34) have reported a related phenomenon, the "proliferation" in vitro of macrophages from patients with tuberculoid leprosy, which occurs in the presence of $M$. leprae and autologous lymphocytes. Tuberculoid macrophages containing bacilli in the absence of such lymphocytes, and lepromatous macrophages containing bacilli in the presence or absence of autologous lymphocytes, fail to proliferate in vitro.

We attempted to determine how well $M$. leprae survive in macrophage cultures from various donors; we found no differences among tuberculoid, lepromatous, and normal control cells in their ability to sustain the viability of $M$. leprae. Indeed, the bacilli fared less well within cells than in the tissue culture medium aloneat least during the 2-wk span of this experiment. It is possible that longer cultivation of $M$. leprae in such preparations may disclose differences among the cell sources.

At the present time it appears that defective lymphocyte function is far easier to demonstrate in patients with lepromatous leprosy than is defective phagocytic cell function. Nevertheless, most defects of lymphocyterelated immune mechanisms demonstrated have occurred in the presence of advanced infection. Under these circumstances, high concentrations of circulating antibody (35), interfering serum factors (36), and depletion of thymus-derived lymphocytes $(10,37-39)$ all have the potential of interfering with the various tests of cellmediated immunity in vitro. When these superimposed features of advanced disease are reversed by chemotherapy, the most clear-cut difference between patients with lepromatous leprosy and other patients lies in their inability to respond to lepromin skin-test material (11). Whether the basic defect in these patients resides in the lymphocyte or in the macrophage remains to be determined. However, the present study indicates that phagocytic cells from patients with either principal form of leprosy function normally in a variety of sophisticated tests of antimicrobial function.

\section{ACKNOWLEDGMENTS}

We thank Dr. Paul Fasal for assistance in obtaining patients with leprosy for study, Dr. Robert Lehrer for assistance in candidacidal studies, and Mr. Joseph McGee and Ms. Maria Chen for technical assistance.

This work was supported in part by grants from the U. S. Public Health Service (AI-10288, AI-07801, and CA-12822).

\section{REFERENCES}

1. Mackaness, G. B. 1971. Resistance to intracellular infection. J. Infect. Dis. 123: 439.

2. Simon, H. B., and J. N. Sheagren. 1972. Enhancement of macrophage bactericidal capacity by antigenically stimulated immune lymphocytes. Cell. Immunol. 4: 163.

3. Patterson, R. J., and G. P. Youmans. 1970. Demonstration in tissue culture of lymphocyte-mediated immunity to tuberculosis. Infect. Immun. 1: 600.

4. Unanue, E. R., and J. C. Cerottini. 1970. The immunogenicity of antigen bound to the plasma membrane of macrophages. J. Exp. Med. 131: 711 .

5. Seeger, R. C., and J. J. Oppenheim. 1970. Synergistic interaction of macrophages and lymphocytes in antigen-induced transformation of lymphocytes. J. Exp. Med. $132: 44$.

6. Turk, J. L., and A. D. M. Bryceson. 1971. Immunological phenomena in leprosy and related diseases. $A d v$. Immunol. 13: 209.

7. Talwar, G. P., A. D. Krishnan, V. L. Mehra, E. A. Blum, and J. M. H. Pearson. 1972. Evaluation of cell mediated immune responses in untreated cases of leprosy. Clin. Exp. Immunol. 12 : 195.

8. James, D. G. 1966. Immunology of sarcoidosis. Lancet. $2: 633$.

9. Brown, R. S., H. A. Haynes, H. T. Foley, H. A. Godwin, C. W. Berard, and P. P. Carbone. 1967. Hodgkin's disease: immunologic, clinical and histologic features of 50 untreated patients. Ann. Intern. Med. 67: 291.

10. Dwyer, J. M., W. E. Bullock, and J. P. Fields. 1973. Disturbance of the blood T:B lymphocyte ratio in lepromatous leprosy: clinical and immunologic correlations. N. Engl. J. Med. 288: 1036.

11. Rees, R. J. W. 1964. The significance of the lepromin reaction in man. Prog Allergy. 8: 224.

12. Barbieri, T. A., and W. M. Correa. 1967. Human macrophage culture: the leprosy prognostic test (LPT). Int. J. Lepr. $35: 377$.

13. Beiguelman, B. 1967. Leprosy and genetics: a review of past research with remarks concerning future investigations. Bull. W.H.O. $37: 461$.

14. Ridley, D. S., and W. H. Jopling. 1966. Classification of leprosy according to immunity: a five-group system. Int. J. Lepr. $34: 255$. 
15. Cline, M. J. 1973. A new white cell test which measures individual phagocyte function in a mixed leukocyte population. I. A neutrophil defect in acute myelocytic leukemia. J. Lab. Clin. Med. 81: 311.

16. Cline, M. J. 1970. Bactericidal activity of human macrophages: analysis of factors influencing the killing of Listeria monocytogenes. Infect. Immun. 2: 156.

17. Drutz, D. J., and M. J. Cline. 1972. Incorporation of tritiated thymidine by leprosy bacilli in cultures of human lepromatous macrophages. J. Infect. Dis. 125 : 416.

18. Lehrer, R. I., and M. J. Cline. 1969. Interaction of Candida albicans with human leukocytes and serum. J. Bacteriol. 98 : 996.

19. Hirsch, J. G., and B. Strauss. 1964. Studies on heatlabile opsonin in rabbit serum. J. Immunol. 92: 145.

20. Klebanoff, S. J., and L. R. White. 1969. Iodination defect in the leukocytes of a patient with chronic granulomatous disease of childhood. N. Engl. J. Med. 280: 460.

21. Levy, L., L. P. Murray, and C. C. Shepard. 1970. A comparative study of mouse foot pad inoculation of skin biopsy specimens from patients with lepromatous leprosy in San Francisco and Atlanta. Int. J. Lepr. 38: 54.

22. Chang, Y. T., and R. N. Andersen. 1969. Morphological changes of Mycobacterium lepraemurium grown in cultures of mouse peritoneal macrophages. J. Bacteriol. $99: 867$.

23. Levy, L. 1972. Prolongation of the lag phase of Mycobacterium leprae by dapsone. Proc. Soc. Exp. Biol. Med. 139: 263.

24. Levy, L. 1971. The effect of freezing and storage at $-60^{\circ}$ on the viability of Mycobacterium leprae. Cryobiology. $8: 574$.

25. Nottebart, H. C., R. F. McGehee, and J. P. Utz. 1973. Cryptococcosis complicating sarcoidosis. Am. Rev. Respir. Dis. 107 : 1060.

26. Aisenberg, A. C. 1966. Immunologic studies of Hodgkin's disease. Cancer. $19: 385$.

27. Casazza, A. R., C. P. Duvall, and P. P. Carbone. 1966. Infection in lymphoma. J. Am. Med. Assoc. 197: 710.

28. Mitsuda, K., and M. Ogawa. 1937. A study of one hundred and fifty autopsies on cases of leprosy. Int. J. Lepr. 5: 53 .

29. Desikan, K. V., and C. K. Job. 1968. A review of postmortem findings in 37 cases of leprosy:, Int. J. Lepr. 36: 32 .

30. Kean, B. H., and M. E. Childress. 1942. A summary of 103 autopsies on leprosy patients on the Isthmus of Panama. Int. J. Lepr. 10: 51.

31. Blumberg, B. S., L. Melartin, M. Lechat, and R. S. Guinto. 1967. Association between lepromatous leprosy and Australia antigen. Lancet. $2: 173$.

32. Patterson, R. J., and G. P. Youmans. 1970. Multiplication of Mycobacterium tuberculosis within normal and "immune" mouse macrophages cultivated with and without streptomycin. Infect. Immun. 1: 30.

33. Godal, T., and R. J. W. Rees. 1970. Fate of Mycobacterium leprae in macrophages of patients with lepromatous or tuberculoid leprosy. Int. J. Lepr. 38: 439.

34. Godal, T., R. J. W. Rees, and J. O. Lamvik. 1971. Lymphocyte-mediated modification of blood-derived macrophage function in vitro; inhibition of growth of intracellular mycobacteria with lymphokines. Clin. Exp. Immunol. 8: 625 .

35. Bullock, W. E., Jr., and P. Fasal. 1971. Studies of immune mechanisms in leprosy. III. The role of cellular and humoral factors in impairment of the in vitro immune response. J. Immunol. $106: 888$.

36. Mehra, V. L., G. P. Talwar, K. Balakrishnan, and L. K. Bhutani. 1972. Influence of chemotherapy and serum factors on the mitogenic response of peripheral leucocytes of leprosy patients to phytohaemagglutinin. Clin. Exp. Immunol. 12: 205.

37. Turk, J. L., and M. F. R. Waters. 1968. Immunological basis for depression of cellular immunity and the delayed allergic response in patients with lepromatous leprosy. Lancet. 2 : 436.

38. Gajl-Peczalska, K. J., S. D. Lim, R. R. Jacobson, and R. A. Good. 1973. B lymphocytes in lepromatous leprosy. N. Engl. J. Med. 288: 1033

39. Bullock, W. E. 1972. Disturbance of lymphocyte circulation by granulomatous infection. J. Clin. Invest. 51: 18a. (Abstr.) 